\title{
On Chinese Loan Words from English Language
}

\author{
Yun Yan \& Tianbai Deng \\ English Department \\ Yangzhou Vocational College of Environment and Resources \\ Yangzhou, Jiangsu, China, 225009 \\ E-mail: yanyun1958@sina.com.cn
}

\begin{abstract}
In the recent twenty years, with China's reform and opening policy to the outside world, there is a sharp increase in English loan words in Chinese. On the one hand, it demonstrates that China's soft power has been booming up. But on the other hand, some language pollution in the meanwhile is caused by non-standard use of loan words in Chinese. This paper probes into some basic concepts of language borrowing as well as some phenomena and reasons of the language pollution through many analysis and examples in order to rectify, regulate and guide the use of English loan words with the prior translation strategy, defending the purity of the Chinese language.
\end{abstract}

Keywords: Chinese loan words, Language borrowing, Language pollution, Purity of Chinese

\section{Introduction}

Nowadays, with the rapid development of human society and the expansion of political, economic and cultural exchanges among different nations, we have more and more opportunities to communicate with the other countries and understand their cultures. The tide of globalization and the intercultural communication make us live in a global village. Intercultural communication is obviously becoming the inevitable tendency we have to face.

Language is not only the most significant tool for human communication, but also the carrier of human civilization and reflection of social reality. Recently there is a heat of learning English in China, at the same time a number of foreign languages file into our country. Therefore, language borrowing has become a very common phenomenon in language development. "The necessities of intercourse bring the speakers of one language into direct or indirect contact with those of neighboring or culturally dominant languages" (Sapir, 2001:159). In the process of communicating with westerners, the borrowing words from English will be the inevitable and important in China. Now we may find a lot of such borrowing words from English everywhere in China, such as soap opera, supermarket, AIDS, rock\& roll, disco, break dance, party and so on.

At present there are about 6000 different languages on our planet, and every one of them has a vocabulary containing many thousands of words. "Whenever and wherever there are contacts of any sort between the speakers of different languages, speakers will make use of words from other languages to refer to things, processes, and the ways of behavior, organization, or thinking for which words or phrases were not available or convenient in their own language hitherto"(Robins, 1996:354). "Everybody is in a position to learn some of the words used by their neighbors, and very frequently people take a liking to some of their neighbors' words and take those words over into their own language"(Trask, 2000:18). These words are termed borrowings, or loanwords which may cover every aspect of human life, including politics, economy, military, culture, art, science, religion and so on. Therefore, we must admit that borrowing from English in Chinese is increasingly unprecedented.

As the English words in China become quite popular among Chinese (especially youngsters) and enriching our Chinese language, some scholars begin to worry about the purity of Chinese - our national language because to some extent, some language pollution has been caused by non-standard use of borrowing. However, at the same time, some scholars can not agree with this opinion. They carry out a series of heated debates, but at last they still can not reach an agreement, which may raise several serious questions deserving our consideration. So how should we look at our national language - Chinese? Shall we accept the existence of the foreign words in Chinese?

This paper probes into the inevitability of language borrowing, such as geography, politics, economy, culture, military as well as some phenomena and reasons of language pollution through lots of analysis and examples in order to advocate the proper use of English borrowings in our modern China.

\section{Background}

\subsection{Concepts and early theories on language borrowing}

According to dictionaries, "loan word" can be defined in many ways. For example, Webster's New World College Dictionary, third edition defines it as "a word of one language taken into another and naturalized"(Neufeldt, 1995); "a 
word in one language that has been borrowed or taken over from another Language" is the definition in Webster's Encyclopedic Unabridged Dictionary of the English Language(Krevisky and Jordan, 1996), and "a word taken into one language from another" in Longman Dictionary of Contemporary English.( Summers, 1993). Besides, in Longman Dictionary of Language Teaching \& Applied Linguistics, loan word is defined as "Borrowing is a word or phrase which has been taken from one language and used in another language. When a single word is borrowed, it is called a loan word."(Richards, 2000). Through history, there are always arguments over the definition of loan word. Some linguists such as Gao Mingkai (1958), Wangli (1988) suggested this term should only refer to phonetic loans; some such as Lv Shuxiang (1942) would rather conclude that borrowings mean both phonetic loans and translated loans.

The writer agrees with the inference that all imported or coined words for new objects, ideas and experiences can be named "loan words", which include hybrid, phonetic and semantic loans. Saussure (2001) pointed out in his lectures that languages have no natural boundaries and there exists "intercourse" between languages and importation of foreign languages in the development of any language. Although he did not make further illustrations about language importation as his real purpose was to demonstrate geographical diversity and coexistence of languages without merging, the statements can presumably be considered as one of the earliest and authoritative arguments on language borrowing in linguistic perspective.

Sapir (2001) pointed out that the simplest kind of influence that one language may exert on another is the "borrowing" of words. When there is cultural borrowing there is always the likelihood that the associated words may be borrowed too. For example, when Christianity was introduced into England, a number of associated words, such as bishop and angel, found their way into English. The process has continued uninterruptedly down to the present day, each cultural wave bringing to the language a new deposit of loanwords.

\subsection{English Loan Words in Chinese}

Shi Youwei (2000:192) analysised the classification of loan words in the book "Loan Words in Chinese" and pointed out that the English loan words used in Chinese concerning every aspect of social life are found in the field of politics, arts and literature, philosophy, economics, mathematics, physics and chemistry, society, culture, education, publication and sports, religion, law, military science, botany and biology, psychology, physiology, geology and geography, building, machinery and communication, textile, clothing and daily necessities, language, foreign affairs.

\section{1) Politics}

Downing street, Whitehouse, Whig,Utopia

2) Arts and Literature

romance, waltz, club, ballet, jazz, tango,cartoon,guitar,model,saxophone

3) Philosophy

science,cynicism,logic

4) Economics

Wall Street,title,Gini coefficient,Bear market,Bull market,Engel curve,trust

5) Mathematics, Physics and Chemistry

aspirin, calorie, cocaine,nylon,nicotine, vitamine, Vaseline,iodine

6) Society, Culture, Education, Publication and Sports

Olympic,Marathon,Ping-pong,lemon,golf,parker,Gypsy,Nike

7) Religion

amen,Mummy,angel,Moslem,Jehovah,Koran,Eden,Christianity,missal,Satan

8) Law

lawyer,bylaw

9) Military Science

rifle, Gatling gun,cannon,tank

10) Botany and Biology

coca,sardine,lemon,Golf,mango

11) Psychology, Physiology, Geology and Geography

tissue,hysteria,Jurassic period,lymph

12) Building, Machinery and Communication 
bus,taxi,microphone, Gothic,jeep,engine

13) Textile, Clothing and Daily Necessities

sofa,flannel,T-shirt,jacket,cigar

14) Language, Foreign Affairs and Others

modern,tip,Uncle Sam,milkshake,humor

So from the examples above we can see that along with the foreign influence on Chinese politics, economics, literature, art, philosophy, science, technology, education, daily life, and many spheres of the Chinese society, foreign languages greatly influenced the Chinese language accordingly.

Generally speaking, perhaps we can classify them into several kinds in terms of areas.

1) On daily life: e.g. green food, Kentucky, toast, Mc Donald's, hot dog, miniskirt, bikini, shampoo, sauna,AIDS

2) On entertainment: e.g. jazz, talk show, soap opera, rock and roll, disco, party, yo-yo, rally, golf, fans, karaoke

3) On morality and ideology: e.g. generation gap, bachelor mother, DINK family, Hippies, cool, streaking, white-collar

4) On science: e.g. colonel, gene, silicon valley, software, hi-tech park, radar, hacker, cyber bar, e-mail, test-tube baby, laser

\subsection{The necessity and restriction of language borrowing}

\subsubsection{External factors inducing language borrowing}

External factors in the intercourse between different languages are essential impetus to language borrowing, without which no language can borrow from another. "The intercourse may be friendly or hostile. It may move on the humdrum plane of business and trade relations or it may consist of a borrowing or interchange of spiritual goods---art, science, religion (Sapir, 1921)." That is to say, language borrowing is normally under the influence of external factors such as geographical neighbourhood, politics, economy, culture, military, and other activities between different countries.

\subsubsection{Restriction of internal factors on language borrowing}

The history of language borrowing in the world shows that borrowing activity between languages is normally restricted by internal factors like morphological form or writing style, phonological pattern and grammatical structure. These internal factors will at least influence the borrowing scale and borrowing manner. Languages of the same writing style usually borrow more easily from each other than those of different styles.

For example, English can easily borrow from Latin, Greek and French in bulk but from Chinese and Japanese only in a comparatively much smaller scale. The reason is not only geographical but also linguistic, because the former group are letter languages while the latter ideographic. Modern Chinese could borrow over one thousand new terms from Japanese with ease because basically the two languages have the same writing style and the borrowed are easily assimilated. Nevertheless, it should be noted that "the ability of the so-called "homogeneous' languages to receive borrowing depends not on the linguistic structures of the language, but on the politico-social position of the speakers" ( Kiparsky, qtd. in Thomason and Kaufman, 1988).

\subsubsection{Major ways of lexical borrowing from English to Chinese}

According to the translative means of loan words, most Chinese scholars divide English borrowings into six categories:

\section{1) Transliteration}

This is to use Chinese characters to imitate the pronunciation of foreign words, thus producing some new words, such as "coffee", "tank", "radar", "sofa", "salon", "model" and "copy", etc.

2) Transliteration plus a word indicating meaning

This way is to add a word indicating the attribute of the original word to the imitation of the whole word's pronunciation and thus readers will be clear of its nature at the first glance, such as the words "beer", "cigar ", "samba " and "golf", "car", "neon", "ballet", etc.

3) Semi-transliteration

This way is to borrow the foreign words both phonetically and semantically, e.g. "ice cream", "Wall Street", "Marxism", "Hacker", "TOEFL", "Pepsi Cola", "Benz", "Shampoo"

4) Free translation

It is one of the most important ways. It can be further divided into two categories: the first is the ordinary meaning translation in which the original words are taken as a whole and new words are created according to their whole original meaning, such as "train", "Esperanto", "Symphony" and "violin"; the second is the "meaning translation with 
imitation" in which the original word structures are retained and new words are formed by combination of Chinese characters, each indicating the meaning of one part in the original words, such as "honeymoon", "football" and "steamboat", etc.

5) Image translation

It is also named as "shape translation" in which the shapes of certain Chinese characters and the images of certain objects are utilized in translation. For example, in those words, such as "I steel", "Z iron", and "Zigzag", the shapes of some characters are ingeniously made use of, and for some other words, such as "peaked cap" and "bow-tie", they are endowed with certain images when entering the Chinese language.

6) Complete loan translation

a. Words borrowed from English directly adding Chinese noun, e.g. "Zhang sir", "ni hao Happy", "B chao", "Web site"

b. Complete letter abbreviation, e.g. "WTO”, "EU”, “APEC", "OPEC”, "IQ”, "MTV”, “CEO”, "MBA", “ATM"

\section{Language pollution in Chinese}

\subsection{Definition of language pollution in Chinese}

In the writer's opinion, language pollution refers to the incorrect or non-standard usage of foreign language which may bring about misunderstanding and inconvenience in the native language.

\subsection{Phenomena of borrowing language pollution}

Based on different reasons and phenomena, we can classify the borrowing language pollution into six categories:

1) Use non-standard translation of loan words, e.g. Kentucky, ice cream, laser. Another case is that Tianmu Zhonglu, a road near Shanghai Railway Station, is spelled three different ways on the street signs. Signs that read Tianmu Zhonglu, Tianmu C. Rd and Tianmu Zhong Rd can be found within several hundreds metres. (Zhong means 'middle' or 'central' in Chinese.)

2) Use unmeaningful transliteration of loan words, e.g. pass, cracker from which people cannot identify clearly.

3) Excessively pursue seemingly western names or terms. For example, it is unnecessary to use a lot of abbreviation of Pinyin in China, such as WBZX coming from Wu Bi Zi Xing, TJ(Tian Jin), GB(Guo Ji), BT(Bian Tai), MM(pretty girl), PSC from Putonghua Shuiping Ceshi, RMB(Chinese currency), etc. There is a case in point, in 2003, one passenger misunderstood the English abbreviation "PVG" (It means "Pu Dong Airport") without any Chinese translation on the airplane ticket, and missed his airplane, causing a loss. At last, he got his compensation from the airport.

4) Use some taboos, four-letter-words or joking words like shit $(\times \times)$, bastard in modern novels, movies and Internet.

5) Add English words in the daily conversation to show the person owns a fashionable style and decent background.

6) Chinglish. If you come across a store with a sign that reads "Sex Shop" or "Adult Shop," don't worry, there are no pornographic products sold on the shelf, it is just a store selling sex health-care medicine or appliances. There is another more ridiculous example, a foreigner was invited to a wedding and there is a line of English greeting in the invitation: "Harmonious Union Lusting a Hundred (It perhaps means "Bai Nian Hao He")". But "lust" in the Holy Bible is one of human's seven original sins. Though the new couple believed their love would last forever, the word 'lust' made them the subject of much laughter.

\section{How to rectify, regulate and guide the use of loan words}

In order to defend the purity of the Chinese language, we should take some rules into account to rectify, regulate and guide the use of English loan words.

\subsection{Consider the restriction of internal factors between different styles like in English and in Chinese}

Language borrowing in the world shows that borrowing activity between languages is normally restricted by internal factors like morphological form or writing style, phonological pattern and grammatical structure. These internal factors will at least influence the borrowing scale and borrowing manner. For example, English is letter language while Chinese is ideographic language. So when we borrow some words between diverse languages especially those of different styles like in English and in Chinese, we should get rid of the language pollution mentioned above.

\subsection{Consider the ways of translation}

Standardization puts emphasis on the common language of all the people, while purity focuses more on keeping the inherent characteristics and advantages of Chinese language. Therefore, in most cases, traditional Chinese terms are more likely to be accepted than the seemingly English words. 
Li Xingian ( Li, qtd. in Shi, 2004), the president of Chinese Newspapers and Periodicals Association, pointed out: "We must advocate to use standard and understandable loan words in our own language. If free translation of some loan words has been established by usage, we should try our best to use free translation rather than transliteration, e.g. WTO, $\mathrm{CEO}$, etc. If we cannot find a proper free translation, we should use transliteration rather than letter abbreviation. If letter abbreviation must be used, we should add to Chinese meaning behind it. But it is unnecessary to use some abbreviation like HSK (Chinese Language Level Examination) and GB (International Standard) which are simply made up by Bopomofo (Pinyin zi mu)."

\subsection{Consider the cultural psychology of the Chinese people}

When we borrow words from other languages, except the internal rules we must abide by, we should consider national cultural psychology. That is to say, we should adapt the loan words to our culture and conventions. For example, "love" is a favorable word in Chinese. If we translate the loan word "AIDS" into "Ai zhi bin", "Ai zi bin", it gives people a kind of irony and satiric feeling. So "Ai zi bin" is comparatively better. For another instance, when many foreign brands are brought into China's market, they usually have their own Chinese names which are beautiful both phonetically and semantically such as Shu Fu Jia (Safeguard), Nai Ke(Nike), Wei Ta Ming(Vitamin), Gao Lu Jie(Golgate), Ke Kou Ke Le(Coca-Cola), etc.

\section{Conclusion}

The preceding study has mainly discussed the language borrowing activities between English and Chinese and some general principles about language borrowing. It is clearly shown that, whether spontaneous or induced, borrowing is one of the important influences on language. "Loanwords" have become an integral part of almost every language and they have contributed greatly to the clarification and richness of native languages.

Language borrowing is usually the natural outcome of language contact and a significant part of language promotion. As a matter of fact, although the direction and scale are different from time to time, language borrowing is prevalent around the world. With the rapid progress of science and technology, especially with the increase of international communication and universal application of internet, languages borrow from each other at an unprecedented rate. Most languages, if not all, manage to widen their vocabularies by borrowing words from other languages. More and more loanwords get established in the native languages; even take the place of the indigenous language. This is the linguistic phenomenon taking place all the time everywhere.

But along with the rapid process of integrating languages together, we should keep alert about the non-standard use of language borrowing and advocate the good use of language borrowing, bringing about the purity of our language as well as the prosperity of our native languages and cultures.

\section{References}

Krevisky, Joseph, and L. L. Jordan. (1996). Webster' s Encyclopedic Unabridged Dictionary of the English Language. New York: Gramercy Books, a Division of Dilithium Press.

Neufeldt, V. (1995). Webster's New World College Dictionary. 3rd ed. New York: Prentice Hall.

Richards, C. J. (2000) . Longman Dictionary of Language Teaching \&Applied Linguistics. Beijing: Foreign Language Teaching and Research Press.

Robins R.H. (2000). General Linguistics. Beijing: Foreign Language Teaching and Research Press.

Sapir, E. (2001). Language: An Introduction to the Study of Speech. Beijing: Foreign Language Teaching and Research Press.

Sussure, F. . (2001). Course in General Linguistics. Beijing: Foreign Language Teaching and Research Press.

Summers, Della. (1993). Longman Dictionary of Contemporary English. Essex: Longman Group UK Limited.

Thomason and Terrence Kaufman. (1988). Language contact, crelization, and genetic linguistics. Berkeley: University of California Press.

Trask, R.L. (2000). Historical Linguistics. Beijing: Foreign Language Teaching and Research Press. http://www.people.com.cn/GB/wenhua/27296/2543319.html. 